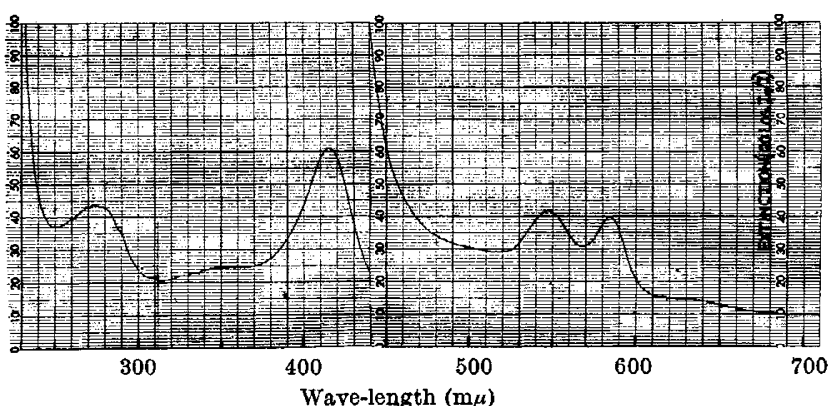

Fig. 1. Absorption-spectrum of aqueous solution of oxyhaemoglobin of Hirudo: extinetion of light $\left(100 \log \left(I_{0} / I\right)\right.$ as a function of wave-length in $\mathrm{m} \mu$. Scanned from right to left. Solution diluted $4 \times$ for wave-ban below $440 \mathrm{~m} \mu$. Artefact at $312 \mathrm{~m} \mu$ marks switch-over from tungsten to
hydrogen lamp

fore possible that the haemoglobin of leeches also has an unusually high oxygen-affinity and that this has adaptive value. At the same time there is at present no reason to think that leeches live under conditions as extremely anoxic as the outstanding values of the $\alpha$-peak of their haemoglobin would imply, and the problem is one of some interest. Internal parasites usually have haemoglobins with a higher oxygen-affinity, and with an $\alpha$-peak at a longer wave-length, than those of their host ${ }^{2}$, but carnivores such as Haemopis and Erpobdella are not even external parasites. Many leeches tolerate stagnant conditions, but these three genera swim well and are presumably not at the mercy of their surroundings. Conceivably a high oxygen-affinity compensates for shortcomings elsewhere in the oxygenation-system.

Department of Zoology,

A. E. NegDham

University of Oxford.

1 Lankester, E. Ray, Proc. Roy. Soc., B, 21, 70 (1872)

${ }^{2}$ Prosser, C. L., and Brown, jun., F. A., Comparative Animal Physiology, 201 (W. B. Saunders, Philadelphia, 1960)

${ }^{3}$ Keilin, D., and Wang, X. L., Biochem. J., 40, 855 (1947).

- Fox, H. Munro, Proc. Roy. Soc., B, 135, 192 (1948); 136, 388 (1949); 138, 514 (1951); 141, 179 (1953); 143, 203, 214 (1955).

\section{Blood Platelets as a Source of Enzyme Activity in Washed Trypanosome Suspensions}

THE standard method used for separating trypanosomes from infected blood involves repeated differential centrifugation of a suspension of trypanosomes and blood elements in a phosphate-buffered saline solution containing glucose. The success of this procedure varies not only from one species to another but also with the degree of parasitaemia. Suspensions of the Liverpool strain of Trypanosoma rhodesiense may be obtained free of red blood cells and leucocytes in this way, but with $T$. vivax, $T$. congolense, $T$. lewisi and the ' $M$ ' and ' $J$ ' strains of $T$. rhodesiense other techniques have to be used for complete removal of blood cells and platelets ${ }^{1,2}$.

In this laboratory, critical microscopic examination of suspensions of the Liverpool strain of $T$. rhodesiense prepared in the foregoing manner showed that, although red blood cells and leucocytes were absent, a quantity of platelets, varying between 12 and 20 per cent of the trypanosome count, was regularly present. Counts were made with a haemocytometer using an untreated glass pipette and the diluting fluid of Cramer and Bannerman ${ }^{3}$. Several techniques, dependent on the size, adhesive or agglutinating properties of platelets ${ }^{2,4-8}$, were tried in order to reduce this contamination. Tho most successful of these for routine separation was the defibrination technique used by Fulton and Spooner ${ }^{2}$; this reduces the contamination to less than 3 per cent and gives a 95 per cent recovery of trypanosomes.

A knowledge of the extent of contamination from blood platelets is essential for any quantitative enzymatic investigations, since platelets exhibit significant metabolic activity ${ }^{8,10}$. Fig. 1 shows the relative contribution of

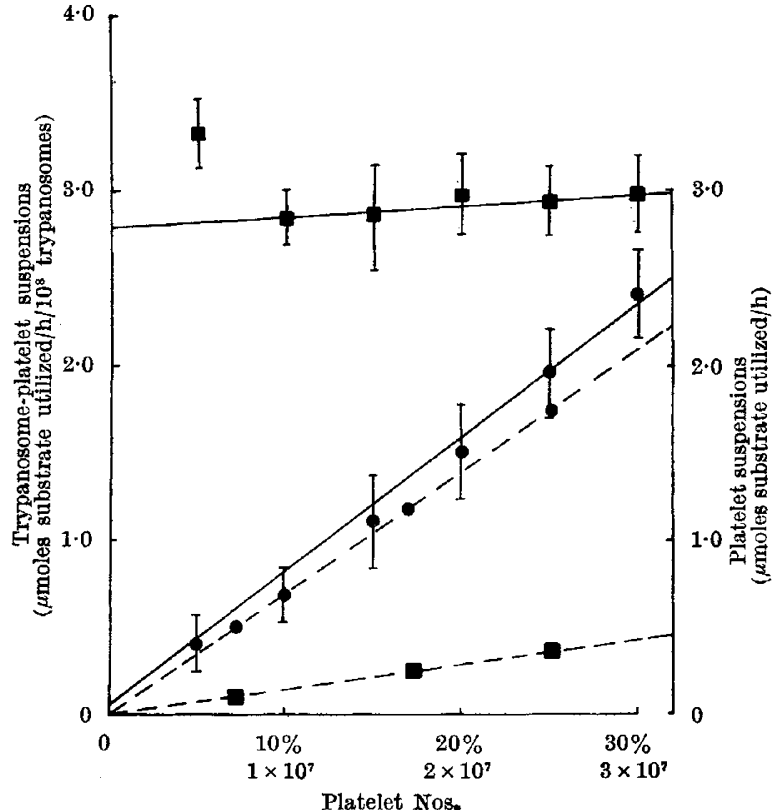

Fig. 1. Enzyme activity of trypanosome and platelet suspensions - Lactic dehydrogenase activity ; $\mathbf{L}$, L-a-glycerophosphate dehydrogenase activity, Each experimental sample $(3.0 \mathrm{ml}$.) contained phosphate buffer, $p$ H $7 \cdot 4(300 \mu$ moles), NADH $(0.5 \mu$ mole), and 0.1 ml. of a whe mixed suspensions contained about $10^{\mathrm{a}}$ trypanosomes $/ \mathrm{ml}$. (10 trypanosomes c. $0.5 \mathrm{mg}$ protein by the biuret method). The platelet suspensions contained between 0.5 and $5 \times 10^{8}$ platelets $/ \mathrm{ml}$. (1 $\mathrm{mg}$ protein c. $9 \cdot 3 \times 10^{8}$ platelets). Sodium pyruvate $(10 \mu$ moles $)$ or a solution of mixed triose phosphate esters $(3.5 \mu$ moles) was added at the start of the experiment

platelets in mixed trypanosome-platelet preparations to L- $\alpha$-glycerophosphate dehydrogenase (GPDH) (Lglycerol-3-phosphate : $\mathrm{NAD}^{+}$oxidoreductase, $E C$ 1.1.1.8) and lactate dehydrogenase (LDH) (L-lactate : $\mathrm{NAD}^{+}$ oxidoreductase $E C$ 1.1.1.27) activity. This activity was determined from the decrease in optical density at $340 \mathrm{~m} \mu$ as reduced nicotinamide-adenine dinucleotide (NADH) was oxidized. The first of these enzymes is part of the coupled dehydrogenase-oxidase system which accounts for the major part of the respiratory metabolism of the blood forms of T. rhodesiense $e^{12,13}$. Lactate dehydrogenase activity has been reported or implied in the same species ${ }^{18-16}$. The present results show that whereas platelets contribute little to the GPDH activity of a $T$. rhodesiense suspension, they are almost entirely responsible for the observed LDH activity. In quantitative enzymatic investigations, therefore, whether of blood parasites or of other blood cells, the possibility of error due to contamination by platelets cannot be disregarded.

I thank Dr. I. B. R. Bowman for his advice and Mr. B. Cover for his assistance.

National Institute for Medical Research, Honor Dixon Mill Hill, London, N.W.7.

${ }^{2}$ Grant, P. T., and Fulton, J. D., Biochem. J., 66, 242 (1957).

${ }^{2}$ Fulton, J. D., and Spooncr, D. F., Exp. Parasitol., 8, 137 (1959).

s Cramer, W., and Bannerman, R. G., Lancet, 1, 229 (1930).

4 Tullis, J. L., Blood, 7, 891 (1952).

- Garvin, J. E., J. Exp. Med., 114, 51 (1961).

Johnson, T. M., and Garvin, J. E., Proc. Soc. Exp. Biol. and Med., 102, 333 (1961).

7 Nordøy, A, and Ødegaard, A. E., Scand. J. Clin. Lab. Invest., 15, 390 (1963).

8 Born, G. V. R., and Cross, M. J., Nature, 197, 974 (1963).

- Zücker, H. B., and Borrelli, J., Ann. N.Y. Acad. Sci., 75, 203 (1958).

${ }^{10}$ Plat, P. M., Bastide, P., and Dastugue, G., Pathol. Biol. Sem. Hô., 11, 352 (1963).

11 Grant, P. T., and Sargent, J. R., Biochem. J., 76, 229 (1960)

12 Grant, P. T., and Sargent, J. R., Biochem. J., 81, 206 (1961).

13 Grant, P. T. Sargent, J. R, and Ryley, J. F., Biochem, J, 81, 200 (1961).

"S Shaw, J. J., Voller, A., and Bryant, C., Ann. Trop. Med. Parasitol., 58, 17 (1964).

${ }^{15}$ Brown, K. N. (unpublished).

${ }_{16}$ Williamson, J., Exp. Parasitol., 2, 348 (1953). 